Iulia COSMA

University of Padua \& West University of Timisoara

Review of: BOASE-BEIER, Jean / FISHER, Lina / FURUKAWA, Hiroko [eds.] (2018):

The Palgrave Handbook of Literary Translation. London: Palgrave Macmillan. 551 p. ISBN: 978-3-319-75753-7

\section{Engaging with Translation. New Readings of George Steiner's After Babel}

Marco Agnetta Larisa Cercel Brian O'Keeffe [eds.]

Yearbook of Translational Hermeneutics Jahrbuch für Übersetzungshermeneutik

Journal of the Research Center Zeitschrift des Forschungszentrums
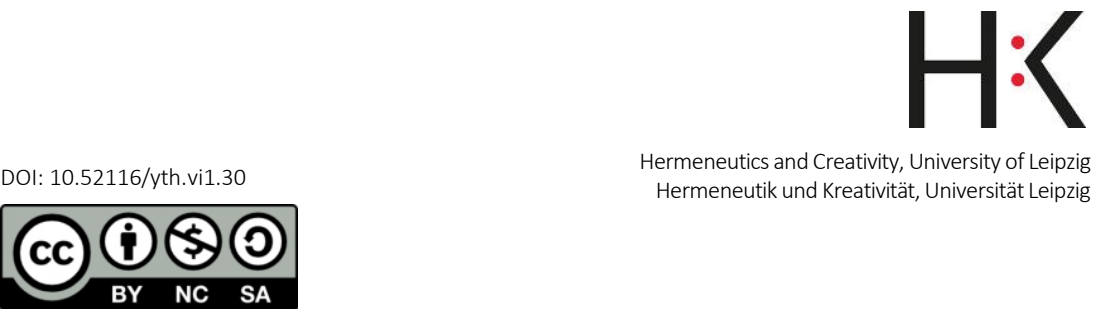

Hermeneutics and Creativity, University of Leipzig Hermeneutik und Kreativität, Universität Leipzig 
Yearbook of Translational Hermeneutics 1/2021 ISSN: 2748-8160 | DOI: 10.52116/yth.vi1.30-37

Iulia COSMA

University of Padua \& West University of Timisoara

Review of: BOASE-BEIER, Jean / FISHER, Lina / FURUKAWA, Hiroko [eds.] (2018): The Palgrave Handbook of Literary Translation. London: Palgrave Macmillan. 551 p. ISBN: 9783-319-75753-7.

From a diachronic perspective and a quantitative standpoint, literary translation was and still is the main topic of interest in translational research. Literary translation studies is involved in an ongoing development of adequate analytical tools and methodologies in order to foster further epistemological advances in the field. Literary translation studies, true to its hybrid nature, willingly crosses disciplinary boundaries and draws on other domains like linguistics, stylistics, comparative literature and literary criticism, to name but a few of the traditional 'hunting grounds' of literary translation scholars. Often, as the editors of this volume rightfully observe in the Preface, a significant part of research undertaken in literary translation studies "starts with a case study of a particular work, or author, of a translator, or of a specific style of the translated text, the way translators read, or the way books are marketed as translations" (p. v). However, "the actual methodologies of case study are rarely discussed. Furthermore, the use of case studies has often been implicit rather than explicit" (ibid.). The three editors' aim is accordingly to strengthen the legitimacy of this practice, first by providing the necessary theoretical grounding, and second by ex- 
ploring the numerous applications of concepts deriving from the social sciences to translational research. Boase-Beier, Fisher and Furukawa achieve their objective by building up a compelling argumentative apparatus articulated much like an e-network, as if to encompass all of the chapters into one 'hyper' case study. The editors' supply a Preface, Introduction and Conclusion, which, gathered together, can be read as a separate text and which are jointly of great importance for expounding the theoretical foundation of translational case study methodology, particularly in view of the authors' intention to illustrate how their approach fits into the case study research paradigm.

The book contains twenty-five essays divided into three wellbalanced sections: literary translation and style, the author-translator-reader relationship, and literary translation and identity. Every contribution is deserving of more than a mention, but the generic conventions of a book review are such that the present review is organized in terms of a synthetic presentation which does not follow the editors' own sections, but is rather assembled around the three primary forms of literature. Poetry translation is examined in relation to cultural and literary history, and moreover with a particular attention to social issues. In "Translating the Poetry of Nelly Sachs", Jean Boase-Beier shows the relevance of context in the understanding of ambiguous poetic texts and the exegetic value of translational criticism when different translated versions of the same poem are discussed from a comparative perspective as interpretative variants. Contrastive analysis in this case is by no means a sterile exercise. In "The Poetry of Gerrit Achterberg: A Translation Problem?", Antoinette Fawcett raises some important questions concerning the invisibility of canonical authors from peripheral literatures outside their literary system, namely authors who, in their country of origin, were deemed particularly difficult to translate, if not untranslatable. Her conclusion is that translation difficulties are not the primary cause of the absence of Achterberg's poetry from the Anglophone market. She also emphasises the major role certain difficulties, especially metrical ones, play in spurring translatory creativity. In this regard, "Transcreating Memes: Translating Chinese 
Concrete Poetry", by Tong King Lee and Steven Wing-Kit Chan, also constitute a testament to translatory creativity. As the authors point out, the problem of 'untranslatability' is related to a certain image of translation as an exact replica of a source-text. But if we go beyond this unrealistic definition, even concrete poetry can be transferred in a different language with admirable results. In "Questioning Authority and Authenticity: The Creative Translations of Josephine Balmer", Susan Bassnett contests the ancillary role of translators and translations in regards to the author and the sourcetext especially when dealing with writers of ancient literature. The question of authenticity must be put in different terms, she argues, when it comes to literary productions that "have been endlessly mediated through the work of many hands" and "have been reconfigured through generations of different aesthetic and ideological criteria" (p. 349). The issue of the authorship of ancient epic is also raised by Kathryn Batchelor in "Sunjata in English: Paratexts, Authorship, and the Postcolonial Exotic", but from a different angle. Her considerations refer to West African Mande oral epic, but they could be extended to other forms of contemporary oral epic or lyric. Assuredly, the more or less tacit appropriation of source-text authorship by the translator is an ethical question that needs to be addressed with all seriousness. In "'Out of the Marvellous as I Have Known It': Translating Heaney's Poetry”, Marco Sonzogni focuses on the author-translator affinity in relation to "places of writing" and its transmutation into "places of translating" (p. 384). Lina Fisher, in "Post-1945 Austrian Literature in Translation: Ingeborg Bachmann in English", highlights the influence exerted by target and source literary criticism on the reception of a translated author. Along similar lines, but from a sociological stance, Francis R. Jones and Richard Mansell discuss the important role played by translators in the promotion of minor literatures and cultures in "Biography as Network-Building: James S. Holmes and Dutch-English Poetry Translation" and "Translators of Catalan as Activists During the Franco Dictatorship" respectively.

Theatrical translation is predominant in the second section. Besides the topic of retranslation, what emerges from the discus- 
sion is the less visible character of this particular type of translation, since it has to do with stage production and what goes on in this regard often remains in-house or takes place behind closed doors. In "Performing the Literal: Translating Chekov's Seagull for the stage", Geraldine Brodie mentions the difficulty of accessing this type of data. She highlights the importance of literal translation in the preparation of a non-literal version for a new theatrical performance and observes that the word-for-word version does not always receive the rightful recognition from those who use it as a primary source. In a similar manner, albeit from a different standpoint, Manuela Perteghella, in "'The Isle is Full of Noises': Italian Voices in Strehler's La Tempesta", examines the case of a fruitful collaboration between an academic translator and the visionary Italian director. Perthegella's definition of theatre translation as "a decision-making process of negotiation among different subjectivities" (p. 270) is supported by the analysis of paratext, epistolary exchanges and marginalia. Janet Garton's paper, 'Ibsen for the Twenty-First Century", completes the picture by discussing scholarly editions of translated drama that are intended to be read, and not performed. Garton illustrates the relevance of that scholarly approach not only in the selection of translators for the Penguin Edition of Ibsen's works, but also in the translation process itself, which she describes as a creativity intensifier.

The remaining contributions (with three exceptions, which will be mentioned in the final part of the review) are dedicated to translated prose. In "Genre in Translation: Reframing Patagonia Express”, Susanne Klinger underlines the importance of readers' expectations in respect of genre. A translation could have the undesired effect of frustrating the reader not because of its poor quality, but because of an editorial operation involving genre shifting which elicits contrasts with source text's stylistic traits. A different aspect of the same phenomenon is studied by Marion Winters. In "The Case of Natascha Wodin's Autobiographical Novels: A CorpusStylistics Approach", she analyses the alterations effected by the English translations of Wodin's first two autobiographical novels written in German. The reduction of sentence length and the short- 
ening of lexical and syntactic repetitions - these being the stylistic hallmarks of Wodin's approach to her autobiographical storytelling - put target-readers in the position where it becomes impossible to notice how "The macro-level effect of these stylistic features is a very intense personal narrative" (p. 163). In "Angst and Repetition in Danish Literature and Its Translation: From Kierkegaard to Kristensen and Høeg”, Kirsten Malmkjaer raises the problem of cross-textual and cross-authorial thematicity in the source-culture and its 'invisibility' in translation. In the opinion of the present reviewer, this is a subject of great importance, not only for translation studies but also for comparative literature. Matthew Chozick, in "Cheating on Murasaki Shikibu: (In)fidelity, Politics, and the Quest for an Authoritative Post-War Genji Translation", follows the editorial and translatory adventures of the eleventh-century Japanese masterpiece, The Tale of Genji, for which we have no definitive source text. Chozick's examination leads him to denounce the manipulation of authorship effected by translators and/or editors in order to gain literary prestige and enable market domination. Hilal Erkazanci Durmuş, in "Hysteresis of Translational Habitus: A Case Study of Aziz Üstel's Turkish Translation of A Clockwork Orange", applies the Bourdieuvan concepts of habitus, field, doxa and hysteresis in order to get a better understanding of Üstel's translatory choices. Durmuş shows how the translator reframes the sourcetext narratives in accordance with his personal experimentation and opinion of the Turkish political and literary fields. In "Translating Voices in Crime Fiction: The Case of the French Translation of Brookmyre's Quite Ugly One Morning", Charlotte Bosseaux illustrates how the question of genre, especially when it comes to a specific kind of literature, like Tartan Noire (i. e. Scottish crime fiction), is correlated to that of local specificity - at issue here, in particular, is the use of dialects or swearing. This is how the characters acquire their specific voices but, faced with the difficulties of rendering dialects or idiomatic uses of language like swearing, these voices are often silenced in the target language version. Thus, crime fiction becomes a great challenge for the translator, but this doesn't mean that he/she is left without options. One, as Bosseaux rightfully sug- 
gests, is that of a collaboration with the author (p. 142) which would help the translator in producing the most pertinent solutions to the difficulties of rendering the latter's stylistic traits in a different language and culture. In "Stylistic Choices in the Japanese Translations of Crime and Punishment', Hiroko Cockerill also tackles the issue of translatory domestication. After undertaking a quantitative analysis, she arrives at the conclusion that, in Japanese translation, "the reduction of the third-person pronouns is the most effective way of removing 'foreignness' from the translated text" (p. 79). Hiroko Furukawa, in "A De-feminized Woman in Conan Doyle's The Yellow Face", addresses the issue of the constraints imposed upon literary traditions and especially the censuring involvement of editors and clients in the final stages of the publication of a translation. Her paper refers to 'women's language' (p. 107), namely an “overfeminizing convention [that] has long been a norm in Japanese literature" (p. 121), a norm which had and still has an ideological function standing in contrast to modern society and women's empowerment but which is still prevalent. In "Translation, World Literature, Postcolonial Identity", Paul F. Bandia investigates "the encounters between cultures of orality and cultures of writing" (p. 499) and the complex process of textualization as a means of creating and claiming an ethnic identity. As Bandia points out, postcolonial writing could be interpreted as a form of translation that blends oral tradition and modernity (p. 503). The paper rises other important questions like the translation of minority cultures in global languages, linguistic innovation and hybridity, and the matter of translation's ethical framework. Along the same lines, Penelope Johnson, in "Border Writing in Translation: The Spanish Translations of Woman Hollering Creek by the Chicana Writer Sandra Cisneros", discusses identity issues, multiculturalism and plurilingualism.

Last, but not least, there are two essays concerning Bible translation and one that considers the preface of a philosophical text. In "The Restored New Testament of Willis Barnstone", Philip Wilson addresses the question of whether religious texts should be interpreted and therefore translated as if they constituted a literary genre. Any answer to this question will inevitably raise strong ideo- 
logical reactions. However, Wilson's paper addresses the matter from a 'scientific', which is to say balanced perspective. The subject of Dror Abend-David's paper, "Divorce Already?! Should Israelis Read the Tanakh (Bible) in Translation?", raises an even more provocative issue since it examines the necessity of intralingual translations for ancient sacred texts. Michelle Bolduc, in "Absence and Presence: Translators and Prefaces", investigates the reasons for the absence of Perlman's preface from the English version of his seminal book L'Empire rhétorique. Bolduc suggests that this omission is due to the "personal nature" of the preface and its being "inflected by literature" since it responded "directly to the work on rhetoric being done in French literary and critical circles of the time" (p. 351f.).

What sets this volume apart is the value of the research resident within its pages but also, and perhaps more especially, the particular attention shown by the editors to the theoretical argumentation, and this in terms of the homogenization of each contributor's essay in such a way that the net result is what one might describe as a kaleidoscopic purview-literary translation presented in its variously coloured facets, in the shifting combination of its different hues, a focusing and re-focusing of the variegated light that translations always shine on the original texts they render. 